\title{
ANALISIS DESKRIPTIF KUALITAS AIR DIKAWASAN PERMUKIMAN DI KOTA PONTIANAK
}

\author{
Muhammad Fikri
}

\section{INTISARI}

Pengelompokan kualitas air di kawasan permukiman sangatlah penting. Tujuan dari penelitian ini adalah untuk menentukan model diskriminan yang terdiri dari faktor dominan pencemaran air. Data yang digunakan dalam penelitian ini adalah data sampel air permukaan yang diambil dari 42 lokasi di Kota Pontianak. Variabel yang digunakan adalah variabel fisik dan kimia. Sampel dianalisis adalah kandungan zat besi (Fe), oksigen terlarut (DO), kebutuhan oksigen biokimia (BOD) dan lebar sungai yang juga dianggap sebagai variabel independen. Langkah-langkah penelitian adalah melakukan uji laboratorium kemudian melakukan statistik deskriptif terhadap masing-masing variabel.

Kata Kunci : Pencemaran air, Deskriptif statistik.

\section{PENDAHULUAN}

Masalah air bersih dan sanitasi merupakan salah satu dari 17 aspek yang harus dibangun berdasarkan dokumen kesepakatan pembangunan global Perserikatan Bangsa-Bangsa (PBB), yang dikenal dengan Sustainable Development Goals (SDGs). Status kualitas air sungai di Kalimantan Barat, khususnya Sungai Kapuas, sudah mencapai kisaran cemar ringan-cemar sedang [1]. Berdasarkan [2] tentang standar baku mutu kesehatan lingkungan dan persyaratan kesehatan air untuk keperluan higiene sanitasi, kolam renang, solus per aqua, dan pemandian umumBerkaitan dengan hal tersebut maka agar air dapat dimanfaatkan secara berkelanjutan dengan tingkat mutu yang diinginkan salah satu langkah yang dilakukan adalah dengan pemantauan dan intepretasi data indikator kualitas air mana saja yang paling berpengaruh. Air untuk keperluan higiene sanitasi tersebut digunakan untuk pemeliharaan kebersihan perorangan seperti mandi dan sikat gigi, serta untuk keperluan cuci bahan pangan, peralatan makan, dan pakaian. Selain itu air untuk keperluan higiene sanitasi dapat digunakan sebagai air baku air minum.

Dalam penelitian ini, Metode Analisis Diskriminan digunakan untuk menganalisis faktor-faktor yang memberikan sumbangan terbesar terhadap terjadinya polusi di Kota Pontianak. Tujuan dari penelitian ini adalah untuk menentukan model diskriminan dan memetakan tingkat pencemaran air di Kota Pontianak secara visual.

\section{Dissolved Oxygen}

Oksigen terlarut (Dissolved Oxygen = DO) dibutuhkan oleh semua jasad hidup untuk pernapasan, proses metabolisme atau pertukaran zat yang kemudian menghasilkan energi untuk pertumbuhan dan pembiakan (Salmin, 2005)[3].

\section{Biochemical Oxygen Demand (BOD)}

BOD atau Biochemical Oxygen Demand adalah suatu karakteristik yang menunjukkan jumlah oksigen terlarut yang diperlukan oleh mikroorganisme (biasanya bakteri) untuk mengurai atau mendekomposisi bahan organic dalam kondisi aerobik (Boyd, 1990)[4].

\section{Besi $(\mathbf{F e})$}

Logam besi $(\mathrm{Fe})$ merupakan logam essensial yang keberadaannya dalam jumlah tertentu sangat dibutuhkan oleh organisme hidup, namun dalam jumlah berlebih dapat menimbulkan efek racun [5].

\section{Chemical Oxygen Demand (COD)}

COD atau Chemical Oxygen Demand adalah jumlah oksigen yang diperlukan untuk mengurai seluruh bahan organik yang terkandung dalam air. Hal ini karena bahan organik yang ada sengaja 
diurai secara kimia dengan menggunakan oksidator kuat kalium bikromat pada kondisi asam dan panas dengan katalisator perak sulfat (Boyd, 1990)[4].

\section{METODE PENELITIAN}

Pengambilan sampel pada penelitian ini berjumlah 42 Sampel air, yang terdiri dari beberapa sungai dan parit yang berada di kota Pontianak. Variabel yang diamati dalam penelitian ini merupakan faktorfaktor yang diasumsikan mempengaruhi pencemaran air permukaan. Berdasarkan [2], standar baku mutu kesehatan lingkungan media air untuk keperluan higiene sanitasi meliputi indikator fisik, biologi, dan kimia yang dapat berupa indikator wajib dan indikator tambahan. Dari indikator tersebut penelitian ini hanya berfokus kepada indikator fisika dan kimia, hal ini dikarenakan keterbatasan biaya yang mahal untuk melihat hasil dari indikator Biologinya. Pengumpulan data penelitian ini menggunakan data primer, yang mana dilakukan penelitian langsung untuk mengambil sampel air, berupa penghitungan secara fisik dan kandungan airnya diperoleh dari bantuan laboran.

Proses analisis diskriminan pada penelitian ini meliputi beberapa langkah yaitu, (1) menentukan variabel-variabel yang diamati menjadi variabel terikat dan variabel bebas. Variabel terikat pada penelitian ini adalah keadaan kondisi air yaitu cemar ringan dan cemar sedang. Variabel bebas yang diamati dari parameter fisik dan kimia adalah kekeruhan (NTU), warna (Pt.Co), besi (Fe) (mg/l), BOD $(\mathrm{mg} / \mathrm{l}), \mathrm{COD}(\mathrm{mg} / \mathrm{l})$ menggunakan rumus penentuan indek pencemaran pada persamaan (2.1) (2) melakukan uji asumsi yaitu uji normal multivariate dan kesamaan varians kovarians setelah dilakukan hanya empat variabel yang memenuhi asumsi yaitu Do (mg/l), BOD $(\mathrm{mg} / \mathrm{l})$, besi $(\mathrm{mg} / \mathrm{l})$ dan lebar sungai $(\mathrm{cm})$ kemudian menentukan metode untuk membuat fungsi diskriminan yaitu metode Step-wise Estimation, dimana variabel dimasukan satu per satu kedalam model diskriminan. Pada proses ini, ada variabel yang akan tetap pada model dan ada juga kemungkinan untuk dikeluarkan beberapa variabel dari modelnya. (3) menguji signifikansi dari fungsi diskriminan yang telah terbentuk menggunakan Wilk's Lambda. (4) menguji ketepatan klasifikasi dari fungsi diskriminan dan mengetahui ketepatan klasifikasi secara individual dengan casewise diagnostic.(5) melakukan interpretasi terhadap fungsi diskriminan.

\section{HASIL DAN PEMBAHASAN}

Baku mutu dan hasil laboratorium Parameter Fisik Air Untuk Keperluan Higiene Sanitasi dapat dilihat pada tabel dan diagram berikut,

\begin{tabular}{clcc}
\hline No & \multicolumn{1}{c}{ Parameter Wajib } & Unit & $\begin{array}{c}\text { Standar Baku Mutu (Kadar } \\
\text { Maksimum) }\end{array}$ \\
\hline 1 & Kekeruhan & NTU & 25 \\
2 & Warna & TCU & 50 \\
3 & Zat Padat Terlarut (Total Dissolved Solid) & Mg/l & 1000 \\
4 & Suhu & $\mathrm{C}$ & Suhu udara 3 \\
5 & Rasa & & Tidak berasa \\
6 & Bau & & Tidak berbau \\
\hline
\end{tabular}

Standar baku mutu yang didapat merupakan ketetapan yang sudah dilakukan oleh peraturan menteri Kesehatan tahun 2013. Dan hasil laboratoriumnya dapat dilihat pada diagram berikut, 


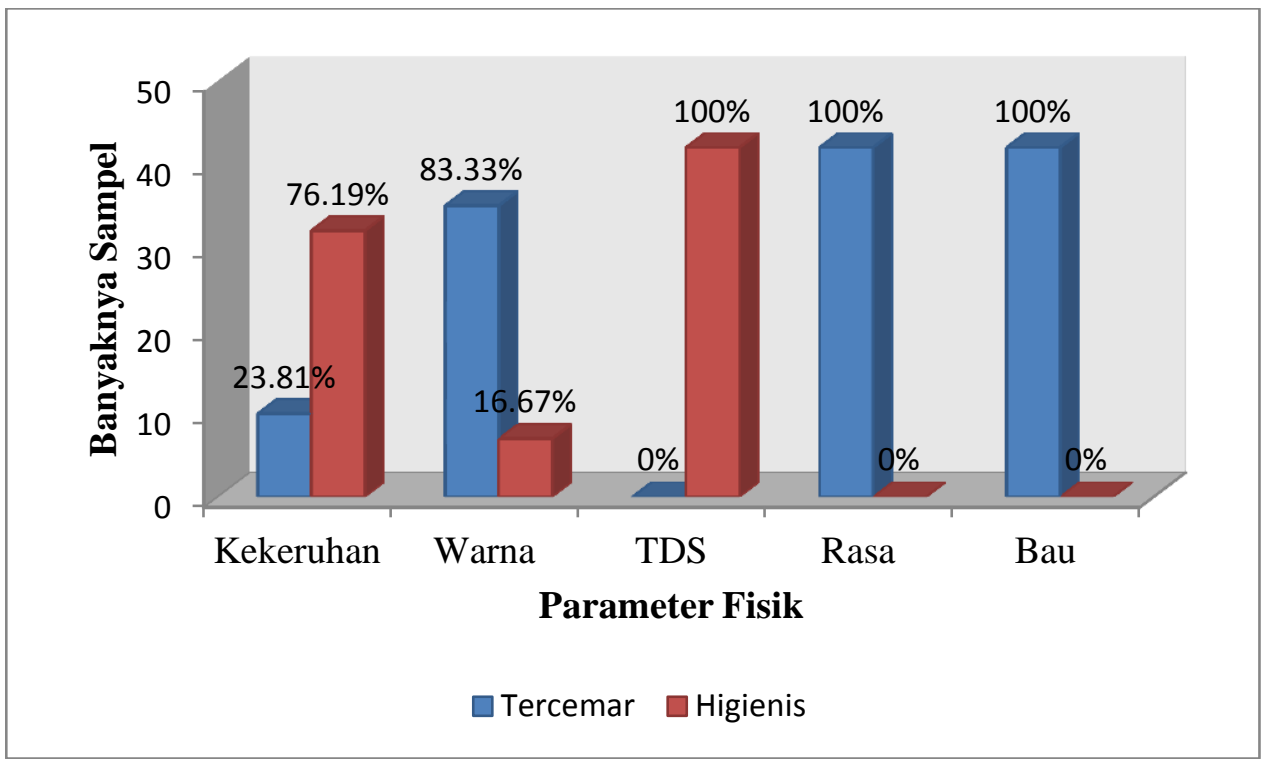

Berdasarkan diagram diatas, terlihat bahwa parameter fisik hampir semua mengalami pencemaran selain TDS. Sehingga dapat disimpulkan bahwa secara fisik air sudah mengalami pencemaran yang sudah sangat signifikan. Maka dari itu perlu penelitian lebih lanjut mengenai peentuan kualitas air secara umum.

Dan berdasarkan parameter kimia dari hasil penelitian laboratorium adalah sebagai berikut

\begin{tabular}{cccc}
\hline No & Parameter Wajib & Unit & $\begin{array}{c}\text { Standar Baku Mutu } \\
\text { (Kadar Maksimum) }\end{array}$ \\
\hline 1 & $\mathrm{pH}$ & $\mathrm{mg} / \mathrm{l}$ & $6,5-8,5$ \\
2 & Besi & $\mathrm{mg} / \mathrm{l}$ & 1 \\
3 & Fluorida & $\mathrm{mg} / \mathrm{l}$ & 1,5 \\
4 & $\mathrm{mg} / \mathrm{l}$ & 500 \\
5 & Kesadahan & $\mathrm{mg} / \mathrm{l}$ & 0,5 \\
6 & Mangan & $\mathrm{mg} / \mathrm{l}$ & 10 \\
7 & Nitrat & $\mathrm{mg} / \mathrm{l}$ & 1 \\
8 & Nitrit & $\mathrm{mg} / \mathrm{l}$ & 0,1 \\
9 & Sianida & $\mathrm{mg} / \mathrm{l}$ & 0,05 \\
10 & Deterjen & $\mathrm{mg} / \mathrm{l}$ & 0,1
\end{tabular}

Dan digram hasil penelitian laboratorium dapat dilihat dibawah ini

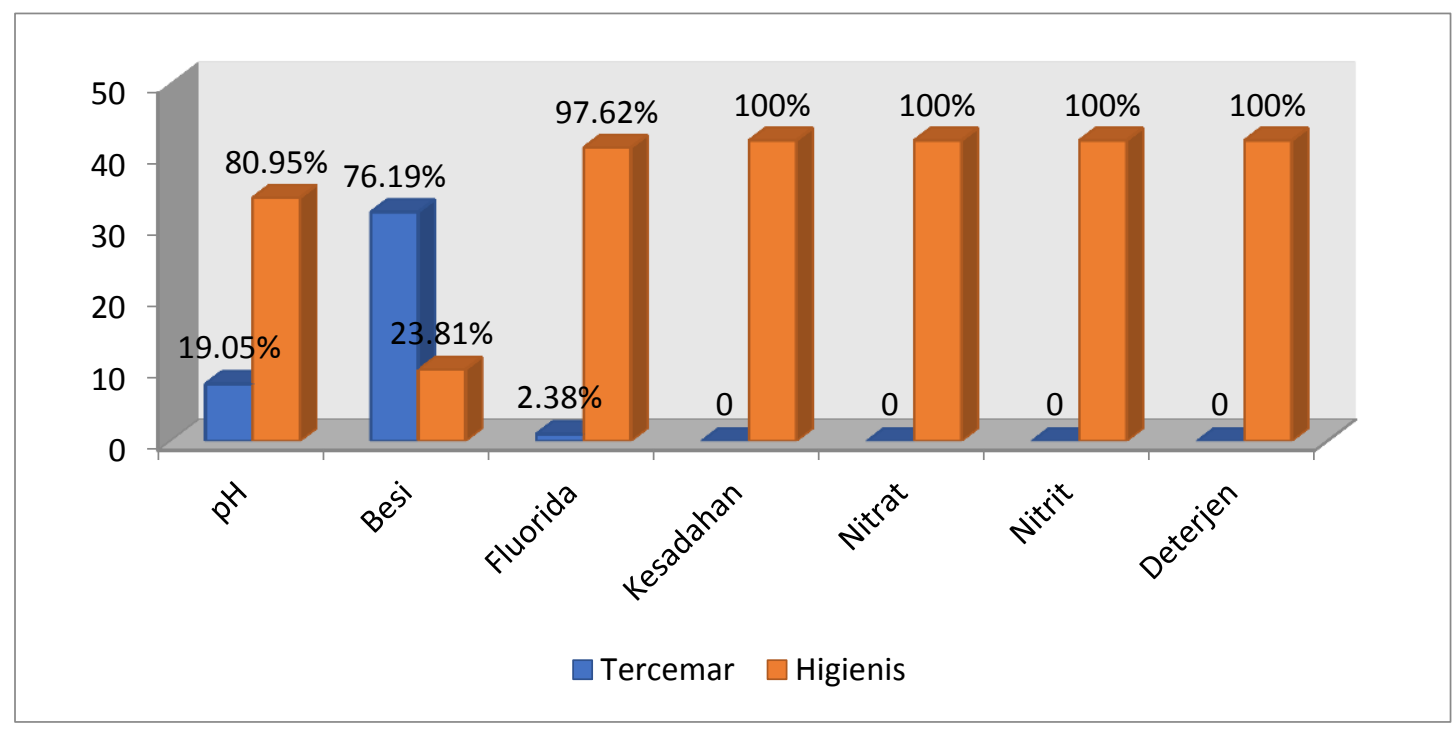


Berdasarkan hasil penelitian, dari tujuh parameter yang diteliti pencemaran tertinggi secara kimia, besi memberikan sumbangan terbesar yaitu sebesar 76,19\% dimana sudah melebihi dari 50\% dari 42 sampel tempat yang diteliti.

\title{
KESIMPULAN
}

Hasil dari penelitian menunjukan bahwa terjadinya pencemaran air sungai di Kota Pontianak berdasarkan parameter fisik dan kimia adalah faktor rasa, bau, warna dan besi yang mana nilai yang diteliti melebihi ambang baku mutu yang telah ditentukan berdasarkan permen yaitu mencapai lebih dari 50\% sampel yang mengalami pencemaran, sedangkan untuk faktor lainnya tidak berpengaruh signifikan terhadap pencemaran air di Kota Pontianak. Berdasarkan hasil ketepatan penelitian antara parameter fisik dan kimia, pencemaran yang paling banyak mempengaruhi pencemaran adalah parameter fisik.

\section{DAFTAR PUSTAKA}

[1] Badan Pusat Statistik. Statistik Indonesia 2018. Badan Pusat Statistik; 2001.

[2] Republik Indonesia. Peraturan Menteri Kesehatan Nomor 32 Tahun 2017 Tentang Standar Baku Mutu Kesehatan Lingkungan dan Persyaratan Kesehatan Air untuk Keperluan Higiene Sanitasi, Kolam Renang, Solus per Aqua dan Pemandian Umum. Sekretariat Negara. Jakarta; 2017.

[3] Salmin. (2005). Oksigen Terlarut ( Do ) Dan Kebutuhan Oksigen Biologi ( Bod) Sebagai Salah Satu Indikator Untuk Menentukan Kualitas Perairan. Oseana ; 2005; 30(3), 21-26. https://doi.org/10.1080/00958970500395898

[4] Boyd, C.E. Water quality in ponds for aquaculture. Alabama Agricultural Experiment Station, Auburn University, Alabama. 482 p;1990.

[5] Supriyantini, E., \& Endrawati, H. (2015). Kandungan Logam Berat Besi (Fe) Pada Air, Sedimen, Dan Kerang Hijau (Perna viridis) Di Perairan Tanjung Emas Semarang. Journal of the Indian Medical Association; 2015; 18(1): 38-45. https://doi.org/10.1111/j.1600-0404.1962.tb01105.x

[6] Republik Indonesia. Peraturan Menteri Lingkungan Hidup Nomor 115 Tahun 2003 Tentang Pedoman Penentuan Status Mutu Air. Jakarta; 2003

\author{
MUHAMMAD FIKRI $\quad$ : Jurusan Matematika FMIPA UNTAN, Pontianak \\ muhammadfikri130797@gmail.com \\ NAOMI NESSYANA DEBATARAJA : Jurusan Matematika FMIPA UNTAN, Pontianak \\ naominessyana@math.untan.ac.id, \\ DADAN KUSNANDAR : : Jurusan Matematika FMIPA UNTAN, Pontianak \\ dkusnand@untan.ac.id
}

